Jennifer Elvira Candra, Roswita Oktavianti: Pengaruh Terpaan Pesan Digital Opinion Leader Terhadap Peningkatan Brand Image Produk (Survey Penonoton Beauty Vlogger Titan Tyra Yang Mengulas Produk Kosmetik Make Over)

\title{
Pengaruh Terpaan Pesan Digital Opinion Leader Terhadap Peningkatan Brand Image Produk (Survey Penonoton Beauty Vlogger Titan Tyra Yang Mengulas Produk Kosmetik Make Over)
}

\author{
Jennifer Elvira Candra, Roswita Oktavianti \\ jenniferelviracandra@gmail.com,roswitao@fikom.untar.ac.id
}

Fakultas Ilmu Komunikasi Universitas Tarumanagara

\begin{abstract}
This research is motivated by the existence of a digital opinion leader who is considered capable of giving an impact and influencing the way of thinking of the audience on a particular product. With the creation of digital opinion leaders they have a role in social media those who have more followers than other individuals. Therefore, many companies or brands use them as part of a marketing strategy. The strength of the message conveyed by them will be able to influence consumer mindset, which will also lead to decisions for the product or brand. Make Over cosmetic brand uses many digital opinion leaders, one of which is Titan Tyra. This research uses two step flow of communication model. From the results of data processing it is known that the independent variable in this study has an effect is 0.891. This means that the relationship between $x$ and $y$ is very strong. Significant results (sig.) Of this study amounted to 0,000 where Sig. Calculate <0.05, which means that the independent variable has a significant effect on the dependent variable, it can be concluded that the exposure to the message of the Digital Opinion Leader has a significant influence on the Brand Image Product.
\end{abstract}

Keywords: Digital Opinion Leader, Brand Image, Two Step Flow Theory, Exposure.

\begin{abstract}
Abstrak
Penelitian ini dilatarbelakangi oleh adanya digital opinion leader yang dinilai mampu memberikan dampak dan mempengaruhi cara berpikir khalayak pada suatu produk tertentu. Dengan terciptanya digital opinion leader mereka mempunyai peran dalam sosial media mereka yang mempunyai pengikut lebih banyak dibandingkan dengan individu lain. Oleh karena itu, banyak perusahaan atau brand yang menggunakan mereka sebagai bagian dari strategi pemasaran. Kekuatan pesan yang disampaikan oleh mereka akan mampu mempengaruhi pola berpikir konsumen, yang sekaligus akan berperan untuk menilai citra dari produk atau brand tersebut. Brand kosmetik Make Over menggunakan banyak digital opinion leader salah satunya Titan Tyra. Penelitian ini menggunakan teori komunikasi model dua tahap atau two step flow of communication model. Dari hasil pengolahan data diketahui bahwa variabel independen dalam penelitian ini mempunyai pengaruh sebesar 0,891. Artinya bahwa hubungan antara $x$ dan y sangat kuat. Hasil signifikan (sig.) penelitian ini sebesar 0.000 yang dimana Sig. Hitung $<0.05$, yang artinya variabel independen berpengaruh signifikan terhadap variabel dependen, maka dapat disimpulkan bahwa Terpaan Pesan digital opinion leader mempunyai pengaruh signifikan terhadap brand image Produk.
\end{abstract}

Kata kunci: Digital Opinion Leader, Brand Image, Teori Komunikasi Dua Tahap, Terpaan.

\section{Pendahuluan}

Era globalisasi, turut membawa perkembangan terhadap aspek Opinion Leader. Salah satunya dengan terciptanya digital opinion leader. Opinion leader mempunyai keunggulan daripada masyarakat kebanyakan. Salah satu keunggulan 
opinion leader yaitu itu lebih mudah menyesuaikan diri dengan masyarakatnya, lebih kompeten dan lebih mengetahui tata cara memelihara norma yang ada di dalam masyarakat (Nurudin, 2009). Sedangkan, Digital opinion leader adalah individu yang mempunyai kemampuan untuk mengubah opini, dan perilaku secara online. Mereka mempunyai peran penting dalam sosial media (Sukardani, 2016).

Menurut Loisa (2012) proses komunikasi interaktif berbasis internet selanjutnya berkembang menjadi media-media sosial maya yang menghubungkan orang-orang dengan minat atau kepentingan yang sama. Dengan demikian, hal ini juga berhubungan dengan khalayak para digital opinion leader yang memiliki ketertarikan yang sama. Para digital opinion leader menggunakan komunikasi persuasif.

Menurut Rogers kegiatan komunikasi persuasif dilakukan dengan saluran media, untuk mendapatkan khalayak atau lingkup yang luas. Saluran komunikasi adalah alat atau media yang dapat dimanfaatkan oleh individu-individu atau kelompok serta organisasi yang berkomunikasi untuk menyampaikan pesan-pesan (messages) mereka (Fatimah dan Cangara, 2016).

Komunikasi persuasif dapat dilakukan oleh para opinion leader dalam model komunikasi massa. Model komunikasi massa yang digunakan oleh para opinion leader adalah model dua tahap atau two step flow of communication model. Tahap pertama merupakan proses dari komunikasi massa. Pada tahap pertama, komunikator menyampaikan atau menyalurkan pesan kepada opinion leader. Tahap kedua merupakan proses komunikasi antar persona, dimana opinion leader semula menjadi komunikan kemudian menjadi komunikator dengan memberikan tanggapan pesan kepada orang-orang yang berinteraksi dengannya (Romli, 2016).

Banyak brand menggunakan digital opinion leader ini sebagai bagian dari strategi pemasaran. Brand tidak hanya mencakup mengenai logo atau nama perusahaan. Brand merupakan imagel citra yang dipersepsikan langsung oleh individu terhadap produk atau perusahaan tersebut. Para digital opinion leader ini dinilai dapat memberikan suatu informasi atau jawaban mengenai suatu produk.

Penelitian ini bertujuan untuk mengetahui apakah terdapat pengaruh signifikan terpaan pesan digital opinion leader terhadap brand image produk.

\section{Metode Penelitian}

Penelitian ini menggunakan pendekatan kuantitatif, dengan metode penelitian survei. Pada penelitian ini, penulis memilih teknik purposive sampling yang terdapat dalam non probability sampling. Purposive samping merupakan metode penetapan responden untuk dijadikan sampel berdasarkan pada kriteria-kriteria tertentu (Siregar, 2013).

Peneliti melakukan survei terhadap 100 responden penonton (viewer) video One Brand Tutorial Make Over yang diunggah Titan Tyra di Youtube. Dalam melakukan penyebaran kuesioner, peneliti menggunakan cara online dengan menggunakan aplikasi google form. Setelah selesai mengumpulkan kuesioner, maka peneliti menganalisis data dengan menggunakan koefisien korelasi, koefisien determinasi, uji analisis regresi linear sederhana dan uji t. Selain itu, penulis juga melakukan keabsahan data dengan menggunakan uji validitas, uji realibilitas,dan uji normalitas. 
Jennifer Elvira Candra, Roswita Oktavianti: Pengaruh Terpaan Pesan Digital Opinion Leader Terhadap Peningkatan Brand Image Produk (Survey Penonoton Beauty Vlogger Titan Tyra Yang Mengulas Produk Kosmetik Make Over)

\section{Gambar 1.}

Kerangka Pemikiran

\begin{tabular}{|c|}
\hline (Variabel X) \\
Terpaan Pesan \\
Frekuensi \\
Durasi \\
Perhatian \\
(Atensi) \\
\hline
\end{tabular}

\begin{tabular}{|l|}
\hline (Variabel Y) \\
Brand Image \\
Favorability of \\
Brand Associations \\
Strength of Brand \\
Assocition \\
Uniqueness of Brand \\
\hline
\end{tabular}

\section{Hasil Temuan dan Diskusi}

Peneliti melakukan analisis terhadap dua variabel, yakni variabel $\mathrm{X}$ (Terpaan Pesan Digital Opinion Leader), dan variabel Y (Brand Image Produk). Peneliti melihat pengaruh dari variabel $\mathrm{X}$ terhadap $\mathrm{Y}$. Berikut adalah hasil uji validitas, uji reliabilitas, koefisien korelasi, koefisien determinasi, uji analisis regresi linear sederhana dan uji t menggunakan aplikasi SPSS 23.0.

Tabel 1. Hasil Uji Validitas Terpaan Pesan Digital Opinion Leader (X)

\begin{tabular}{ccc}
\hline Pernyataan $(\mathrm{X})$ & $\begin{array}{c}\text { Corrected Item- } \\
\text { Total Correlation }\end{array}$ & Keterangan \\
\hline K1 & .572 & Valid \\
K2 & .654 & Valid \\
K3 & .804 & Valid \\
K4 & .773 & Valid \\
K5 & .779 & Valid \\
K6 & .730 & Valid \\
K7 & .582 & Valid \\
K8 & .544 & Valid \\
K9 & .823 & Valid \\
\hline
\end{tabular}

Sumber: SPSS Ver.23.0

Tabel 2. Hasil Uji Validitas Brand Image Produk (Y)

\begin{tabular}{ccc}
\hline Pernyataan (Y) & $\begin{array}{c}\text { Corrected } \\
\text { Total Correlation }\end{array}$ & Keterangan \\
\hline L1 & .843 & Valid \\
L2 & .830 & Valid \\
L3 & .897 & Valid \\
L4 & .877 & Valid \\
L5 & .831 & Valid \\
L6 & .846 & Valid \\
L7 & .826 & Valid \\
L8 & .848 & Valid \\
L9 & .795 & Valid \\
L10 & .851 & Valid \\
L11 & .853 & Valid \\
\hline
\end{tabular}

Sumber: SPSS Ver.23.0 
Pengujian validitas dilakukan dengan menjadikan 0.200 sebagai patokan terhadap kolom Corrected Item-Total Correlation. Berdasarkan Tabel 1 dan 2, nilai dari Corrected Item-Total Correlation lebih besar dari 0.200 maka hasil uji variabel $\mathrm{X}$ dan variabel Y dinyatakan valid seluruhnya.

Tabel 3. Hasil Uji Reliabilitas

\begin{tabular}{llll}
\hline Variabel & N & Cronbach's & Keterangan \\
\hline & & Alpha & \\
$\begin{array}{l}\text { Terpaan Pesan Digital } \\
\text { Opinion Leader }\end{array}$ & 9 & 0,912 & Reliable \\
Brand Image Produk & 11 & 0,969 & Reliable \\
\hline
\end{tabular}

Sumber: SPSS Ver.23.0

Uji Reliabilitas suatu kuesioner memiliki butir instrumen yang dapat dikatakan reliable jika nilai Cronbach's Alpha melebihi 0.6. Maka, penelitian ini dapat dikatakan reliable karena nilai Cronbach's Alpha pada variabel X da Y melebihi 0.6.

Menurut Siregar (2013:251), nilai korelasi 0.00-0.199 mempunyai hubungan yang sangat lemah, nilai korelasi 0.20-0.399 mempunyai hubungan yang lemah, nilai korelasi 0.40-0.599 mempunyai hubungan yang cukup, nilai korelasi 0.60-0.799 mempunyai hubungan kuat, dan nilai korelasi 0.80-0.100 mempunyai hubungan yang sangat kuat.

Nilai koefisien korelasi (R) untuk variabel independen Terpaan Pesan Digital Opinion Leader (X) adalah sebesar 0,891. Artinya bahwa hubungan antara x dan y sangat kuat.

Berdasarkan Tabel 1, diperoleh hasil koefisien determinasi dengan menggunakan nilai $\mathrm{R}$ square yaitu sebesar 0,794, yang berarti bahwa pengaruh variabel Terpaan Pesan Digital Opinion Leader (X) terhadap Brand Image Produk (Y) adalah sebesar 79.4\%. Sisanya yaitu sebesar 20.6\% (100-79.4) dipengaruhi oleh faktor-faktor lain yang tidak dijelaskan dalam penelitian ini.

Tabel 5. Analisis Regresi Linear Sederhana variabel X dengan variabel Y

\begin{tabular}{|c|c|c|c|c|c|c|}
\hline Model & & $\begin{array}{l}\text { Unsta } \\
\text { Coeff }\end{array}$ & lized & $\begin{array}{l}\text { Stand } \\
\text { dized } \\
\text { Coeff } \\
\text { ents }\end{array}$ & & \\
\hline & & B & $\begin{array}{l}\text { Std. } \\
\text { Error }\end{array}$ & Beta & $\mathrm{t}$ & Sig. \\
\hline & $\begin{array}{l}\text { (Consta } \\
\mathrm{nt})\end{array}$ & 6.894 & 1.960 & & 3.517 & .001 \\
\hline & $\begin{array}{l}\text { Terpaan } \\
\text { Pesan }\end{array}$ & 1.403 & .072 & .891 & 19.426 & .000 \\
\hline
\end{tabular}

Sumber: SPSS Ver.23.0

Berdasarkan Tabel 2, nilai Standardized Coefficients adalah 0.891, artinya variabel x mempengaruhi variabel y $89.1 \%$. Dapat dikatakan bahwa pengaruh dari variabel independen dalam penelitian ini tergolong sangat kuat. Sementara itu, nilai sig pada Tabel 2 adalah 0.000 yang < (kurang dari) 0.05. Maka dapat 
Jennifer Elvira Candra, Roswita Oktavianti: Pengaruh Terpaan Pesan Digital Opinion Leader Terhadap Peningkatan Brand Image Produk (Survey Penonoton Beauty Vlogger Titan Tyra Yang Mengulas Produk Kosmetik Make Over)

disimpulka bahwa variabel independen (terpaan pesan digital opinion leader) dalam penelitian ini memberi pengaruh yang signifikan terhadap variabel dependen (brand image produk).

Gambar 2. Grafik Uji Normalitas P-Plot

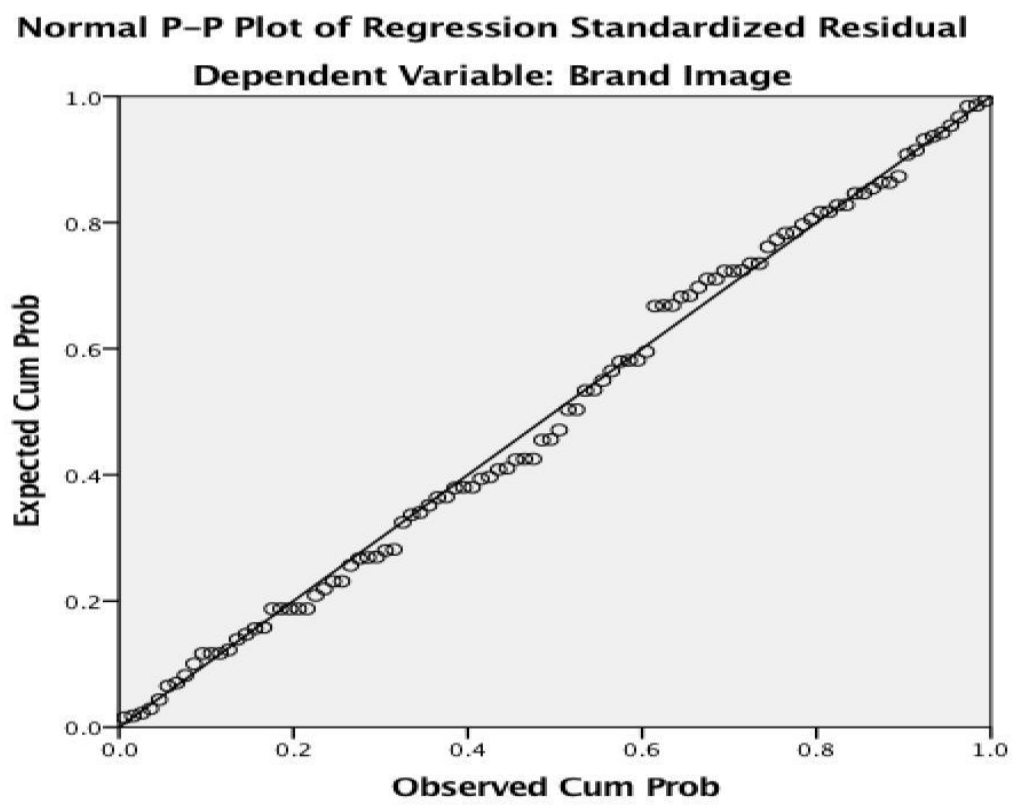

Sumber: SPSS Ver.23.0

Berdasarkan Gambar 1, dapat dilihat bahwa terlihat titik-titik menyebar disekitar garis diagonal, dan titik-titik tersebut mengikuti arah garis diagonal, maka grafik ini menunjukkan bahwa penelitian dapat dikatakan normal.

Dalam teori komunikasi two step flow of communication, pesan yang diterima oleh individu opinion leader, mempunyai perhatian lebih pada media massa, sehingga mereka menjadi orang yang terinformasi, dan akan menginterprestasikan pesan tersebut sesuai dengan frame of reference dan field of experience. Setelah itu, para opinion leader akan menyampaikan pesan tersebut kepada khalayaknya. Dalam kasus penelitian ini, Titan Tyra sebagai opinion leader dari brand Make Over. Video yang diunggah Titan Tyra di Youtube memberikan pesan-pesan persuasif, informasi dan kegunaan dari brand Make Over tersebut, yang akan di tonton oleh khalayaknya serta akan mempengaruhi niat khalayaknya agar tertarik pada produk Make Over tersebut.

Digital opinion leader mampu menghasilkan pesan persuasif yang dapat mengubah sikap audience, dan mempengaruhi niat mereka untuk membeli suatu produk (Nunes,dkk.,2017). Para digital opinion leader yang mencitrakan produk melalui kanal digital dan sosial media akan membawa pengaruh terhadap penjualan dari sebuah brand/produk (Sukardani, 2016).

Menurut Gani (dalam Oktavia, Loisa, dan Oktavianti, 2017), dalam masyarakat pedesaan, opinion leaders-lah yang bisa meneruskan informasi dari media ke masyarakat. Hal ini tentu berbeda dengan masyarakat perkotaan yang mengandalkan media massa sebagai sumber informasi. Meskipun demikian, opinion leaders yang memanfaatkan sosial media, seperti Youtube tetap memberikan pengaruh bagi responden. 
Menurut Ardianto, Komala, dan Karnilah (2007), variasi volume informasi dari opinion leader menyebabkan efek yang positif pada khalayak, maka akan menguntungkan pihak sumber. Dalam Video One Brand Tutorial Make Over yang diunggah Titan Tyra di Youtube, Titan Tyra memberikan banyak informasi positif dan berguna mengenai produk Make Over, sehingga dengan adanya informasi tersebut, akan menguntungkan pihak brand Make Over, salah satunya adalah dengan meningkatnya citra atau image dari produk Make Over.

\section{Simpulan}

Berdasarkan hasil analisis dan pengolahan data, maka dapat disimpulkan bahwa terdapat pengaruh yang sangat kuat terpaan pesan digital opinion leader terhadap brand image produk sebesar 0.891. Ho ditolak dan Ha diterima, yang artinya variabel terpaan pesan opinion digital leader (X) memiliki pengaruh terhadap brand image produk (Y). Sehingga, penelitian ini juga berpengaruh signifikan karena hasil sig. Hitung <0.05 dengan demikian, penelitian ini tidak hanya berpengaruh kepada sampel, tetapi juga berpengaruh kepada populasi.

\section{Ucapan Terima Kasih}

Atas terselesaikannya penelitian ini, peneliti mengucapkan terima kasih kepada orang tua yang memberikan dukungan dan doa, Ibu Roswita Oktavianti S.Sos., M.Si., selaku pembimbing skripsi, serta responden yang membantu penulis untuk bersedia mengisi kuesioner.

\section{Daftar Pustaka}

Ardianto, E., Komala, L., \& Karlinah, S. (2007). Komunikasi Massa Suatu pengantar edisi revisi. Bandung: Simbiosa Rekatama Media.

Fatimah, S., \& Cangara, H. (2016).Pemanfaatan Saluran Komunikasi Dalam Penyerapan Aspirasi Masyarakat Oleh Pusat Pelayanan Informasi Dan Pengaduan (PINDU) Pemerintah Kabupaten Pinrang. Jurnal Komunikasi Karebo, 79.

Loisa, R. (2012). Strategi Komunikasi Politik: Facebook, Kesadaran Kritis, Dan Aksi Politik Di Dalam Revolusi Mesir. Jurnal Komunikasi , 1-16. Jakarta: Universitas Tarumanagara

Nunes, R. H., Ferreira, J. B., de Freitas, A. S., \& Ramos, F. L. (2017). Opinion Leader in Social Media. Review of Business Management, 57.

Nurudin. (2009). Sistem Komunikasi Indonesia. Jakarta: Rajagrafindo Persada

Oktavia, C., Loisa, R., \& Oktavianti, R. (2017). Pengaruh Terpaan Pesan Portal Berita Media Online dan Opinion Leaders Terhadap Perubahan Aktivitas Bermedia Sosial. Koneksi, 279-284.

Romli, K. (2016). Komunikasi Massa. Jakarta: Grasindo.

Siregar, S. (2013). Metode Penelitian Kuantitatif: Dilengkapi dengan PerbandinganPerhitungan Manual \& SPSS. Jakarta: Prenada Media Group

Sukardani, P. S. (2016). Brand Communication Melalui Digital Influencer. Universitas Negeri Surabaya, 3-7 